\title{
Using hydropower waterway locks for energy storage and renewable energies integration
}

\author{
Gilton Carlos de A. Furtado ${ }^{1}$, André Luiz A. Mesquita ${ }^{2}$, Alessandro Morabito ${ }^{3}$, Patrick Hendrick ${ }^{4}$, Julian D. Hunt ${ }^{5}$ \\ ${ }^{1}$ Amazon Development Center in Eng., Federal University of Pará, Brazil. giltoncar@gmail.com (Corresponding Author) \\ ${ }^{2}$ Amazon Development Center in Eng., Federal University of Pará, Brazil. andream@ufpa.br \\ ${ }^{3}$ Aero-Thermo-Mechanics Dept., Université Libre de Bruxelles (ULB), Brussels, Belgium. alessandro.morabito@ulb.ac.be \\ ${ }^{4}$ Aero-Thermo-Mechanics Dept., Université Libre de Bruxelles (ULB), Brussels, Belgium. patrick.hendrick@ulb.ac.be \\ ${ }^{5}$ International Institute for Applied System Analysis (IIASA), Laxenburg, Austria, hunt@iiasa.ac.at
}

\begin{abstract}
Waterway are one of the most efficient means for transportation. It can be applied for energy storage demonstrating the potential of using these structures with renewable energy systems, here, through an analysis of energy alternatives. This paper analyzes two different solutions for energy supply, using the Locks of the Tucuruí powerplant, in Brazil. A photovoltaic power station is compared to a hybrid system composed by photovoltaic and pumped storage. The alternatives are discussed technically and economically. The energy costs of the scenarios are calculated based on the evolution of the expenses and the related payback time are found. The water resource is exploited responsibly, keeping balanced the pumped and turbined volumes of water. The grid works as an intermediate storage and allows the operations with a single pump-turbine conversion. Its location lowers down the initial investment in favor of the hybrid system as the more viable alternative. It was found that the locks could be used to handle up to $263 \mathrm{~kW}$ and $387 \mathrm{~kW}$ of electricity in turbine and pump mode, respectively. This paper gathers crucial data on the use of hydropower in waterways locks that support the integration of renewable energies surrounding the locks. In addition, the use of pumped storage plants to store energy from intermittent sources, present themselves as an innovative opportunity to, using the own head available at facility, improve the financial return of meeting the energy demand through an economically and environmentally responsible energy system, may be useful in similar facilities around the world.
\end{abstract}

Keywords: Hybrid system, Tucuruí Locks, Photovoltaic energy, Pump As Turbine (PAT), Renewable Energy Sources (RES).

\section{NOMENCLATURE}

$\begin{array}{llll}A, B, C & \text { Coefficients of the speed equation } & P_{P V} & \text { PV module nominal power } \\ a, b, c & \text { Coefficients of pump equation } & P_{m 1}, P_{m 2} & \text { Solar power of the alternatives } 1 \text { and } 2 \\ A_{P V} & \text { Area of PV module } & Q & \text { Flow rate } \\ C_{O \& M_{H y b}} & \text { Operation and maintenance hybrid cost } & \operatorname{Red}_{1}, \operatorname{Red}_{2} & \text { Factors of reduction } 1 \text { and } 2 \\ C_{O \& M_{P V}} & \text { Operation and maintenance photovoltaic cost } & T O E & \text { Tariff of energy } \\ C_{C a p_{H y b}} & \text { Hybrid capital cost } & t & \text { Time } \\ C_{C a p_{P V}} & \text { Photovoltaic capital cost } & t_{0} & \text { Time of operation } \\ C_{A q} & \text { Cost of equipment acquisition } & t_{H y b} & \text { Hybrid system payback } \\ C_{A v} & \text { Cost of availability } & t_{P V} & \text { Photovoltaic system payback } \\ C O E_{C_{y e a r}} & \text { Cost of energy per year } & U & \text { Velocity } \\ C O E_{H y b} & \text { Cost of hybrid energy } & V & \text { Volume } \\ C O E_{P V} & \text { Cost of photovoltaic energy } & z & \text { Static level } \\ C O E_{C} & \text { Annual cost of energy } & \eta & \text { Efficiency }\end{array}$

The short version of the paper was presented at ICAE2019, Aug 12-15, Västerås, Sweden. This paper is a substantial extension of the short version of the conference paper. 


\begin{tabular}{|c|c|c|c|}
\hline$C O E_{w d}$ & Cost of energy (working days) & $\alpha$ & Demand factor \\
\hline$C O E_{w k}$ & Cost of energy (weekend) & $\rho$ & Density of water \\
\hline$C_{P V}$ & Cost of photovoltaic system & Subscripts & \\
\hline$d$ & Demand & $P A T$ & Pump as turbine \\
\hline$d_{s}, e_{s}$ & Coefficients of system equation & $0,1,2$ e 4 & Conditions \\
\hline$E$ & Energy & at & Current condition \\
\hline$E_{s 1}, E_{s 2}$ & Solar energy for alternatives 1 and 2 & $t$ & Turbine \\
\hline$g$ & Acceleration of gravity & $s$ & System \\
\hline$G_{\text {sol }}$ & Hourly solar irradiation on the site & máx & Maximum \\
\hline$h_{l T}$ & Head losses & $\min$ & Minimum \\
\hline$H$ & Head & $b$ & Pump \\
\hline$H_{S P}$ & Peak sun-hour & req & Required \\
\hline$L_{A}$ & Energy demand & $w d$ & Working days \\
\hline$N_{1}, N_{2}$ & Rotational speed at conditions 1 and 2 & $w k$ & Weekend \\
\hline$N_{P V 1}, N_{P V 2}$ & Number of panels for alternatives 1 and 2 & $e$ & Facility \\
\hline$N_{b}$ & Number of pumps & $i$ & Instant \\
\hline$p$ & Pressure & $P V$ & Photovoltaic \\
\hline$P_{1}, P_{2}$ & Power of pump at conditions 1 and 2 & inv & Inverter \\
\hline
\end{tabular}

\section{INTRODUCTION}

Waterways are the most efficient means for transportation and the only land infrastructure with the free capacity not subject to congestion problems. Navigation is the energy and carbon-efficient mode as a ship uses 1 to 2 times less fuel than a train and 3 to 5 times less fuel than a truck and can be economically competitive [1]. Additionally, waterways can be built with pumped storage plants together with intermittent energy sources, present themselves as an innovative opportunity to, using the own head available at facility, improve the financial return of meeting the energy demand for a solar hybrid generation system with pumped storage.

In the city of Tucuruí, Brazil, the dam of the hydropower plant on the Tocantins river creates a water height difference of $61.7 \mathrm{~m}$. Two locks allow the water transport and passage of local goods in the state of Pará. The operation of these locks is under the responsibility of the National Department of Transport Infrastructure (DNIT), regardless of the adjacent hydroelectric plant.

Several studies have been conducted in regard of the environmental effects of the Tucurui dam and its upper reservoir. Curtarelli et al. [2] investigate, by mathematical modeling, the carbon emission due to the formation of the Tucurui reservoir. The authors demonstrate that the quantity emitted in the lake is of the order of $1.1 \mathrm{Tg}$ of carbon per year, highlighting the importance of the carbon inventory in energy systems and the use of less environmental impact resources. Chen et al. [3] show the impact patterns in deforestation and forest degradation due to the construction of the aforementioned hydropower plant. The implementation of such a large infrastructure (the fifth hydropower station in the world) have affected the local biodiversity in addition to the consequences of urban development.

Today, it is important to reduce the environmental and carbon footprint of dam's appliances as the locks of the waterways. Renewable energy sources (RESs) are now considered an important and strategic way of ensuring the sustainability of projects $[4,5]$ and the coupling with energy storage systems contributes in their optimal exploitation in terms of reliability $[6,7]$ operations $[7,8]$ and return of investment $[9]$.

Further investigations on the use of RES combined with energy storage for standing alone system can be found in the literature. Ma et al. [10] study the optimization of the sizing of renewable energy system for electrification of isolated areas without access to the grid, highlighting the importance of storage for the success of the project aiming at continuity and reliability due to the intermittency of the solar source. Malheiro et al. [11] also study energy optimization and programming in stand-alone systems. Evaluating a hybrid system with solar, wind and diesel sources as a backup supply, mathematically analyzes, within a year, the hourly changes in the availability of sources and energy demand. Considering that hybrid energy systems are increasingly used in isolated or energy-deficient areas, Aziz et al. [12] demonstrate that an optimized system is more economical and reliable than a power system with a single source. Ma et al. [13] study the 
optimization of a hybrid solar-wind system with pumped storage to serve an isolated grid with a capacity of the order of a few hundred kW. Pali and Vadhera [14] propose a new configuration of a hybrid system with wind and hydro sources for rural and isolated areas. Connecting the wind turbines directly to the energy storage, the authors highlight the cost reduction and improvements in simplicity and reliability regardless of the wind power fluctuations. Thus, the application of hybrid systems, even considering the peculiarities of each situation, can be useful in different scenarios of energy needs [5].

Researchers put particular effort into RES solutions connected with pumped hydro energy storage (PHES), which has today the most used technology in terms of capacity worldwide. Kusakana [15] proposes an optimal energy dispatch model by using a combination of solar, wind, diesel sources and PHES in order to meet the variable demand: this modelization tackles the seasonality and the intermittency of RES, which represents a continuous challenge for energy management systems (EMS). EMS of hybrid solutions counts further complexity due to the diversity and variability of diverse sources $[4,5,12-14,16,17]$. Analyzing the traditional scenario of power generation, Bhattacharjee and Nayak [4] analyze the application of a solar hybrid system with pumped storage searching a viable, continuous and cost-effective solution to the problem of low water availability in power plant reservoirs, demonstrating it as a good option for restoring the reservoir's performance. Xu et al. [17] observe consistent load fluctuations due to the variability of wind and solar sources that, on a large scale, can cause stability and safety threats in the electricity network. Besides, PHES can cause instabilities due to the interaction between shaft vibration and governing strategies during the connection and disconnection of the system [17].

Morabito and Hendrick [18] study a solar, wind and PAT hybrid system connected to a smart grid in a real application. The prototype uses a speed control to guarantee the operation of the machine in the BEP according to the suitable hydrological conditions, what highlights the importance of the study in the field of hybrid systems integrated to the grid.

Another aspect of energy generation from renewable sources is the operational and storage limitations of each source. $\mathrm{Ma}$ and Javed [19] present an integrated design of a hybrid system with solar, wind and battery storage considering the saturation limits for each source, based on economic and technical indexes. Javed et al. [20] propose a hybrid system with stored pumping and batteries as an off-grid renewable energy system. The authors use a new operating strategy based on the maximum extraction of energy stored at the point of maximum PAT efficiency, with the battery used only to meet very low levels of load. To evaluate the performance of the system, a general indicator of storage overall performance, energy utilization ratio and storage usage factor is used. In this way, the need to know the limiting characteristics of each source proposed as a solution is highlighted.

Hybrid systems may be viable in other types of power generation. Stenzel and Linssen [21] present an application concept and a new form of pumped storage using federal waterways as a lower reservoir in Germany, identifying a potential of $400 \mathrm{MWh}$. An energy solution for the transposition system is proposed by Zhang et al. [22]. The authors present a project of potential energy exploration using the head and flow in the operations of filling and draining. The authors demonstrate viable applications that seek maximum utilization of energy availability, even in facilities or places intended for other purposes. The costs involved in the design, installation and maintenance are decisive in the adoption and determine the viability of renewable energy systems. An adequate economic approach to energy systems can be carried out considering the annual cost and the payback of the systems [23, 24] or the effective cost using the net present value method [25] including availability, efficiency, installation, operation and maintenance costs.

The varied research and applications of hybrid energy systems show the feasibility of these solutions for energy supply in isolated areas, integrated into the grid, etc. However, the implementation of RES in Locks presents an interesting gap that can be investigated, with very few studies in the literature. For the Brazilian case, there are more than 20 Locks and more than a hundred other dams [26], in which the combination of head and solar radiation is very frequent, thus allowing the use of both sources for energy generation and storage. The results of which can easily be applied to hydroelectric plants and transposition systems worldwide.

In this work, in particular, the study to demonstrate the potential of using these structures with renewable energy systems focuses on performing an analysis of energy alternatives for the operation of the Tucurui locks considering two possible scenarios: one with pure photovoltaic energy supply and the other one with a hybrid system composed of solar and hydraulic sources, with pumped hydro energy storage. Moreover, the economic feasibility of each alternative and the payback is investigated. The evaluation of the alternatives studied shows that the hybrid system with pumped storage is 
more economically (around 40\%) and technically feasible due, mainly, to the availability of head and the high costs of a purely photovoltaic plant.

This paper is structured as follows: in section 2 a brief description of the site, location and main characteristics of the hydrological use is presented. Availability to use potential and solar energy is shown. Section 3 contains the work approaches regarding the proposed solutions to meet the energy demand of the facility, the systems designed, the selection of machines and the calculation of PAT performance in pump mode. The methodology for calculating energy costs and payback time for each proposal analyzed is also presented. Section 4 discusses the results of the analysis from the previous section and, finally, the conclusion is presented in section 5 .

\section{CHARACTERISTICS OF TUCURUÍ LOCKS}

The Tucurui hydroelectric plant is the fifth largest in the world and has an installed capacity of $8535 \mathrm{MW}$, distributed in 25 hydraulic generating units with $22.5,350$ and $395 \mathrm{MW}$ power capacity. The turbines take advantage of a $61.7 \mathrm{~m}$ net head maintained by an earth and rock dam of over $11 \mathrm{~km}$. Its spillway is designed for a maximum flow of $110,000 \mathrm{~m}^{3} / \mathrm{s}$, characterizing it as the world's largest in spillway capacity. This feature allows the possibility of exploitation of the water resource due to the water spill that occurs during some months each year.

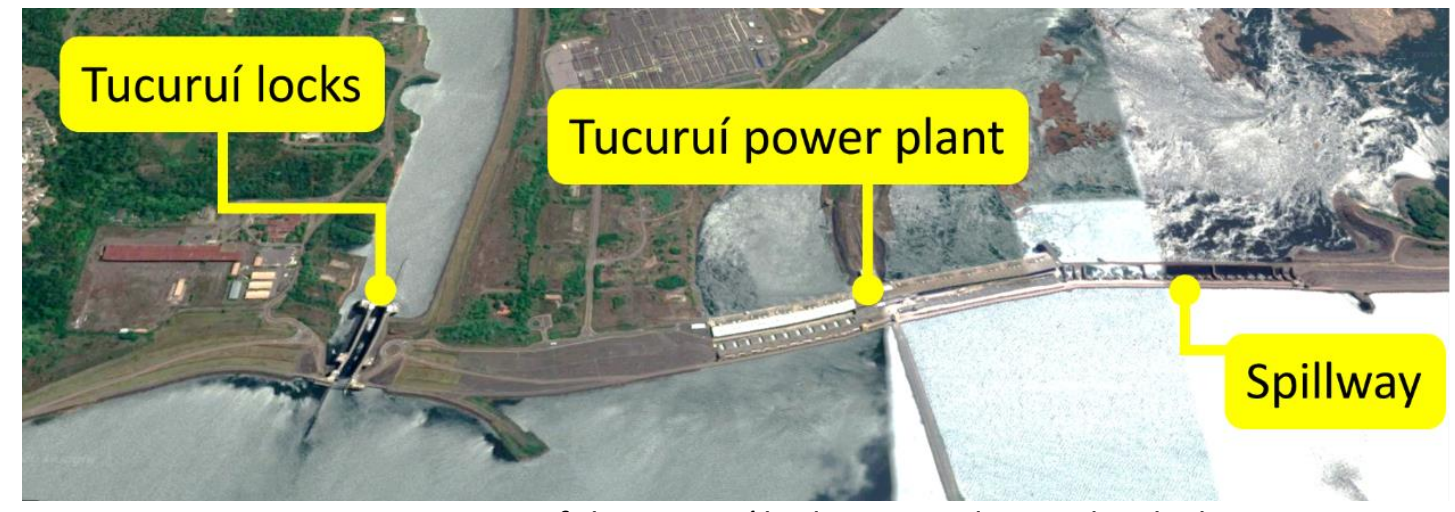

Figure 1. Overview of the Tucuruí hydropower dam and its locks.

The Tucuruí locks, showed in Figure 1, are installed in an area where the incident solar insolation allows for a utilization of the solar resource at an average cost of $1.8 \mathrm{US} \$ \mathrm{Wp}$. The average daily solar irradiance of the selected site is depicted in Figure 2. In addition, the installation is located in the same existing dam structure and it allows the possibility of take advantage of the head for generation aiming to self-consumption. In this context, Figure 3 shows the variation of the head over a hydrological cycle.

The head variation is related to the natural seasonality of the Tocantins River and the power generation of the plant. The difference between the effluent and turbined flow rate gradually changes the head, causing it to vary by up to $15 \mathrm{~m}$ over a year. As it shares the same upper reservoir, Lock 1 is also subject to variation in the head, although the downstream level, which is independent of the powerplant's lower reservoir, remains constant. 


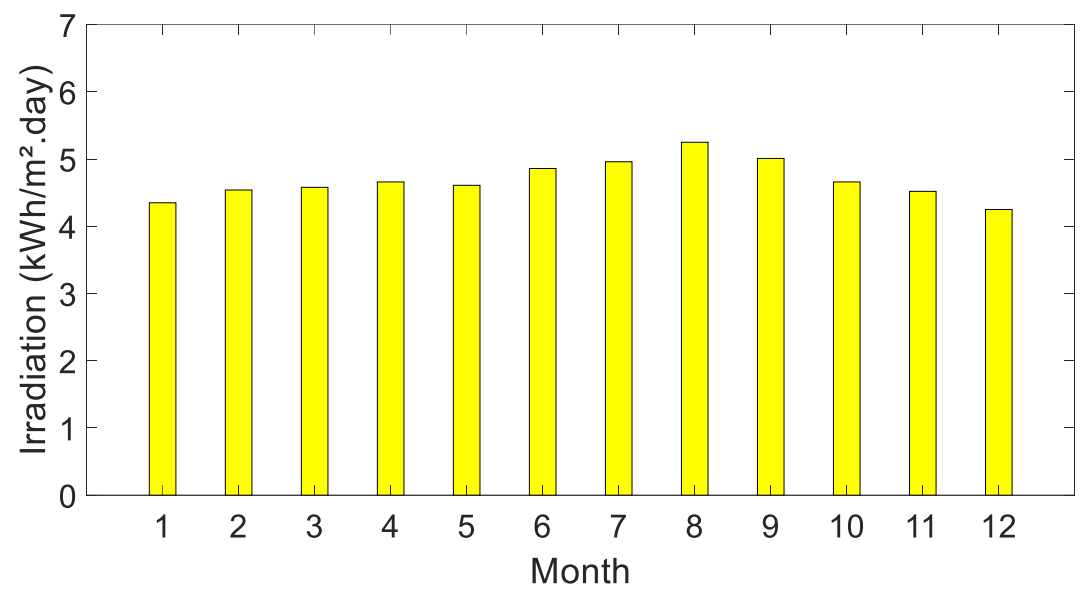

Figure 2. Average monthly irradiation in the site.

The transposition system studied is composed of two locks connected by a channel that allows trains maneuvers and crossings in navigation. Each structure is $210 \mathrm{~m}$ long, $33 \mathrm{~m}$ wide and is designed to operate independently of each other. The filling and draining operations are carried out in approximately 30 minutes, with capacity to handle up to 19 thousand tons of load, in trains of $200 \mathrm{~m}$ length, $32 \mathrm{~m}$ wide and $3 \mathrm{~m}$ draft [27].

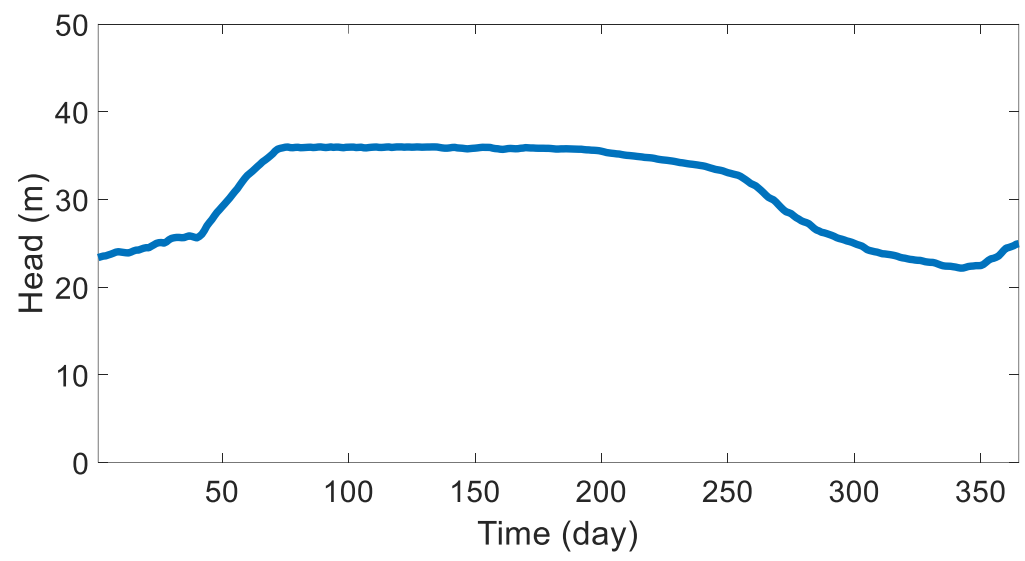

Figure 3. Head over a year in the site.

This geographical area benefits from a good sun exposure as demonstrated by Jannuzzi and Melo [28]. Based on the experience of developed countries, the application of photovoltaic systems follows a trend established by the combination of the continuous reduction of the costs of the solar modules with the increase of the tariffs of conventional electric power [29]. The data available for solar irradiation in the Brazilian territory show an enormous potential for renewable energy production, although these values are subject to overestimation [30]. However, European countries, which receive lower solar insolation take advantages of good policies for regulating renewable energy. An analysis of hybrid systems connected to the grid is presented by Martins et al. [31] showing the feasibility and usefulness in the energy planning.

\section{ANALYSIS OF ENERGY ALTERNATIVES}

\subsection{Demand}

For the calculation of the demand profile, the following procedure was performed. The total energy consumed in the transposition operations, which includes filling and draining, and the functioning of the control system was measured directly in the energy meters of the Locks in two months. The one of greatest consumption was considered, in which the total energy for operation of the installation $E_{O}$ was $135,090 \mathrm{kWh}$. From this, the daily average of 4,503 kWh was calculated. In equation (1), the quantity $n$ represents the maximum number of 16 maneuvers per day, established in the design, based on which the energy required for each maneuver was calculated, within the hours of operation of the facility. 
Each transposition maneuver is carried out in about 30 minutes, for that reason, Figure 4 presents the demand profile with this resolution. Alternatively, therefore, every half hour the energy consumption $d_{e}$ varies from a maximum value, related to transposition, and a minimum value referring to the general operation of the plant in terms of lighting, administrative services, auxiliary machinery and equipment etc. The adoption of time interval $i$ in Equations (1) to (3) establishes the amount of energy being consumed at each moment, between the maximum and minimum values. Thus, the demand at each instant $d_{e}$ can be written analytically as following.

$$
\begin{aligned}
& d_{i}=\left\{\begin{aligned}
0, & i<9 \\
0.1, & i=9,11,13 \ldots \\
0.9, & i=10,12,14 \ldots \\
0, & i>40
\end{aligned}\right. \\
& 0 \leq i \leq 48
\end{aligned}
$$

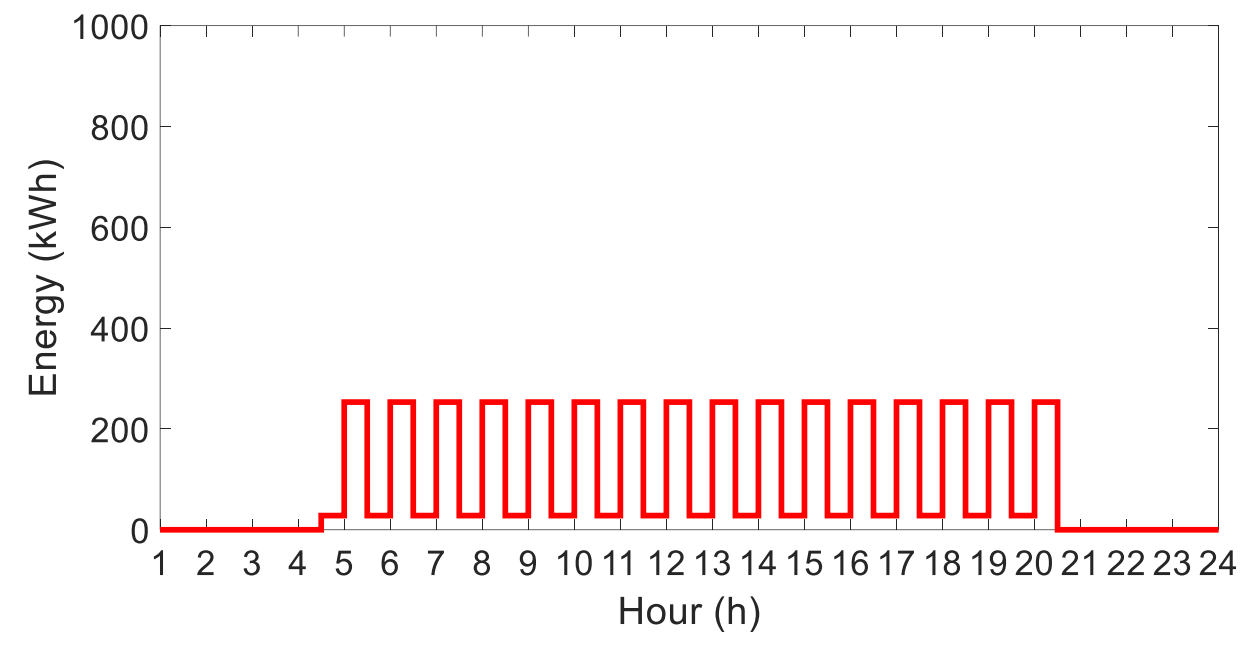

Figure 4. Facility demand.

\subsection{Photovoltaic-only alternative}

The solar power $P_{m 1}$ for this alternative was calculated based on Equation (4), proposed by Pinho and Galdino [32] that takes into account the lowest irradiation in year $H_{S P}$ and energy demand $L_{A}$ plus reduction factors related to dirt, permanent degradation throughout use, lower manufacturing tolerance, temperature losses and system losses including wiring, controller, diodes etc.

$$
P_{m 1}=\max _{j=1}^{12}\left[L_{A} /\left(H_{S P} \operatorname{Red}_{1} \operatorname{Red}_{2}\right)\right]
$$

The solar irradiation data at the site $H_{S P}$ were obtained from CRESESB [33] and, as shown in Figure 5, presents in December the lowest average incidence, as considered in the $P_{m}$ estimate. For the factors $\operatorname{Red}_{1}$ and $\operatorname{Red}_{2}$, the values of 0.75 and 0.90 , respectively, were considered. 


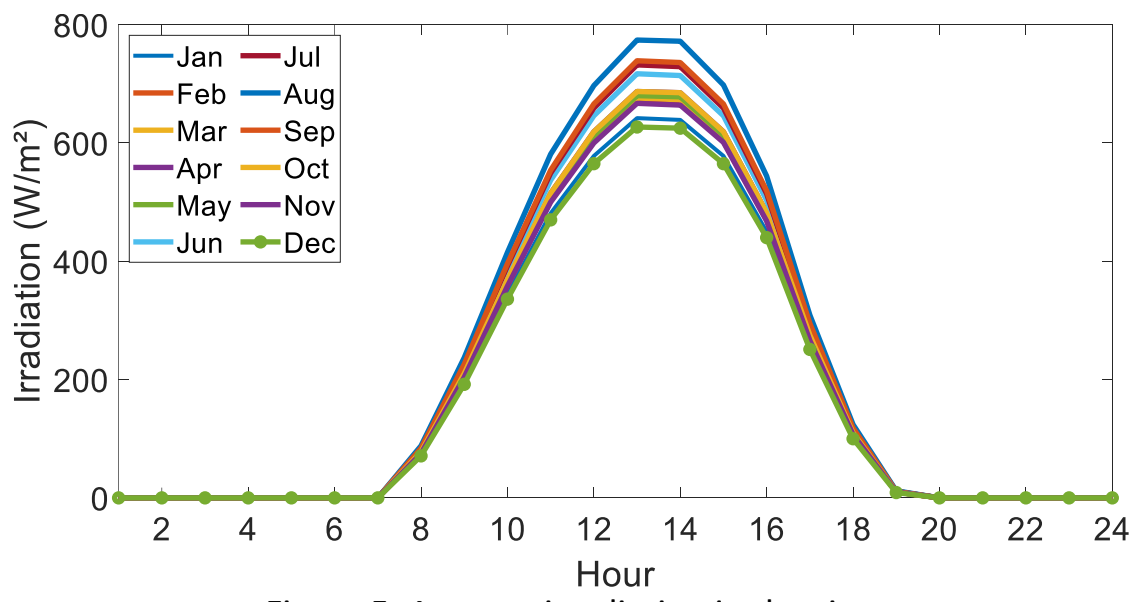

Figure 5. Average irradiation in the site.

For the designed system the model cs6u-330p photovoltaic module with efficiency of $16.97 \%$ and rated power $P_{p}$ of $330 \mathrm{~W}$, of Canadian manufacture, was selected. Relating this to the solar power $P_{m 1}$, the number of panels $N_{P V 1}$ required was calculated. Hourly solar energy, for the purely photovoltaic case, $E_{s 1}$, was determined by Equation (5), which relates the performance characteristics of the photovoltaic module with the received radiation. The methodology proposed by Pinho and Galdino [32] through Equation (5) presents an estimate for the photovoltaic project.

$$
E_{s 1}=G_{s o l} N_{P V 1} A_{P V} \eta_{P V} \eta_{i n v}
$$

The solar photovoltaic system is the first energy alternative analyzed in order to meet the energy demand for the operation of the Locks. This application would use the grid as storage in form of energy compensation, according to the rules of the National Electric Energy Agency.

\subsection{Hybrid system alternative}

The hybrid system has been designed with the aim of adding a cheaper solution with shorter return of investment time [34], grid stability [17] and the possibility of rapid corrections in operational quantities to respond to changing demands of the facility and solar incidence on site. A system consisting of a photovoltaic solar source and a hydraulic source using PATs was designed, shown in Figure 6.

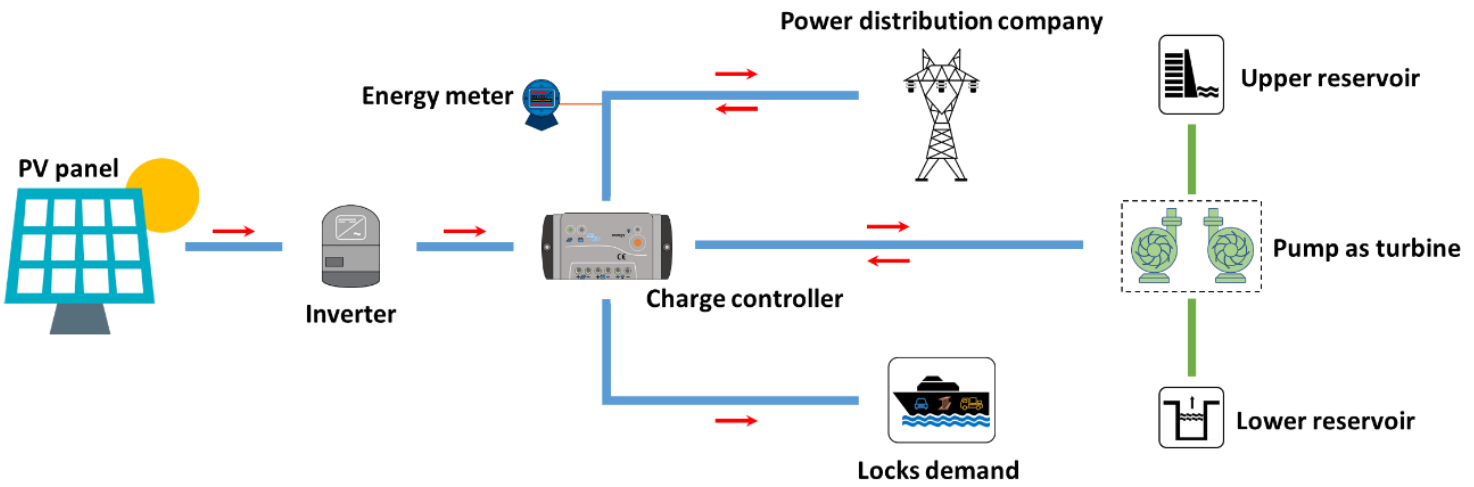

Figure 6. Schematic arrangement of the proposed hybrid system.

The power supply for the installation can come from different sources. The first option considers a $100 \%$ photovoltaic generation. The second form can be supplied directly by the grid, in which energy is generated in a conventional manner, for example, at the adjacent hydroelectric plant, through a Francis turbine. Finally, a hybrid solar-hydraulic form with a percentage of each source in the system. The appropriate choice of this factor, referred as $\alpha$ in Equation (6), must be carried out through an optimization process that offers the most attractive value in terms of cost and efficiency, in 
different consumption and generation scenarios, such as example, that performed by Wang and Huang [35,36]. The design of the hybrid system, by font optimization, is not the scope of this work. Calculations testing different percentages were carried out, pointing the value of $50 \%$ as more attractive, although refinement is required, which will be the subject of a future work. This factor is proposed with the objective of sizing the hybrid system, considering the period of less solar and head availability. However, the generation of each source to meet the demand must be analyzed considering the specific scenarios at each moment, in view of their variation throughout the year.

The possibility of the pump operating as a turbine associated with a speed regulator guarantees the flexibility needed to meet the above-mentioned variations. PAT has its operational quantities defined by the correlation between solar energy and demand at each moment. This difference, positive or negative, is transferred to the hydraulic machine and defines its pump or turbine mode. In this model the energy, consumed or produced, is determined every half hour, as shown in Figure 12.

Considering the design criterion $\alpha=0.5$, which means the percentage that the demand that the photovoltaic system was designed to meet, the solar power, number of modules and hourly solar energy were calculated according to Equations (6) to (8). The variation at each instant of solar incidence $G_{s o l}$ is shown in Figure 5.

$$
\begin{aligned}
P_{m 2}= & \alpha \cdot L_{A} /\left(H_{S P} \operatorname{Red}_{1} \operatorname{Red}_{2}\right) \\
& N_{P V 2}=P_{m 2} / P_{P V} \\
E_{S 2}= & G_{s o l} N_{P V 2} A_{P V} \eta_{P V} \eta_{i n v}
\end{aligned}
$$

PAT energy is calculated by the difference between demand and solar production at each instant of time, according to Equation (9).

$$
E_{P A T}=d_{e i}-E_{s 2}
$$

This difference is the energy that must be generated by PAT, whose magnitude will imply the selection of the machine according to the flow rate given by the Equation (10), within the compatibility between the maximum $H_{\text {máx }}$ and minimum head $H_{\min }$ of the system and those established by the manufacturer. With the efficiency considered 0.8 the operational limits of the project were calculated, as shown in Table 1.

$$
Q_{P A T}=\frac{E_{P A T}}{\rho g H \eta_{t} t_{0 t}}
$$

This operational configuration, however, establishes a lot of number of conversion or implies a large change in speed. Since the facility has a connection to the power distribution company, it is possible use this feature as an intermediate storage source, transferring the energy balance from the hourly basis to the daily basis.

\subsection{Use of water resource}

To determine the water volume, flow rate and consequently the operating point for selection of suitable machine, Equation (11), which represents the energy in a hydraulic turbine, was used. For initial purposes an efficiency $\eta_{t}$ of 0.8 was considered. Head $H$ is defined by the hydrological condition of the day, and its variation over a hydrological cycle is shown in Figure 3.

$$
E_{t}=\rho g H Q_{t} \eta_{t} t_{0 t}
$$

Considering that $Q_{t}=V_{t} / t_{0 t}$, the equation can be rewritten to determine the volume of water used in the production of energy $E_{t}$, as follows: 


$$
V_{t}=E_{t} / \rho g H \eta_{t}
$$

The use of water resources in the responsible exploitation of the site was an established concept for the installation project, so that in one day of operation, the pumped volume is equal to the turbine, according to Equation (13).

$$
V_{t}=V_{b}
$$

From the equality relationship between turbine and pumped volumes, the total flow rate in pump mode was calculated considering the operating time in direct mode $t_{0 b}$, as follows:

$$
Q_{b}=\frac{V_{b}}{t_{0 b}}
$$

The quantity $Q_{b}$ is the total flow rate pumped by the energy $E_{b}$ during an operating day. In this work, in order to research and explore the behavior of PATs operating in parallel, a number $N_{b}$ of four machines was established for the composition of the operation scheme.

\subsection{The selection of the machines}

The pump selection process was based, a priori, on the characteristics of the installation, such as head and flow rates, as shown in the previous items. The prediction of the behavior of the pump selected to operate with turbine will be the subject of research and future articles. The proper pump was determined considering the seasonal variations of head due to Tucuruí lake level variation. Thus, two limit curves were calculated for the system, shown in Figure 9. The minimum and maximum flow rates for the project $Q_{b m i n}$ and $Q_{b m a x}$ were calculated according to Equations (15), for the maximum and minimum heads, respectively.

$$
Q_{b \min }=\left.\frac{Q_{b}}{N_{b}}\right|_{H_{\text {máx }}} \text { and } \quad Q_{b m a ́ x}=\left.\frac{Q_{b}}{N_{b}}\right|_{H_{\text {min }}}
$$

The operating range for a pump was calculated according to Equations (15), which determine the operating points for commercial selection by crossing the flow rate lines with the system curves. For the case under study, the following characteristics were calculated, shown in Table 1. From the maximum head and minimum flow rate point, a model BMI 2503301750 rpm pump manufactured by IMBIL was selected.

Table 1. Installation characteristics.

\begin{tabular}{l|c|c|c}
\hline \multicolumn{1}{c|}{ Quantity } & Symbol & Value & Unit \\
\hline Maximum head & $H_{\text {máx }}$ & 36 & $m$ \\
\hline Minimum head & $H_{\min }$ & 22 & $m$ \\
\hline Time in turbine mode & $t_{0 t}$ & 7,5 & $h$ \\
\hline Time in pump mode & $t_{0 b}$ & 9 & $h$ \\
\hline Pump minimum flow rate & $Q_{b \min }$ & 700,38 & $\mathrm{~m}^{3} / h$ \\
\hline Pump maximum flow rate & $Q_{b m a ́ x}$ & 1146,1 & $\mathrm{~m}^{3} / h$ \\
\hline Number of pumps & $N_{b}$ & 4 & - \\
\hline Maximum flow rate of the facility & $Q_{\operatorname{máx}}$ & 4584,4 & $\mathrm{~m}^{3} / h$ \\
\hline
\end{tabular}




\subsection{The facility}

The project consists of a facility for energy use taking advantage of the existing structure of the Locks. The chamber, in its internal structure, has an unused aqueduct for communication between upstream and downstream levels independent of the filling and draining system, which can be utilized for the project. Figure 7 shows the existing structure and a schematic representation of the planned project.

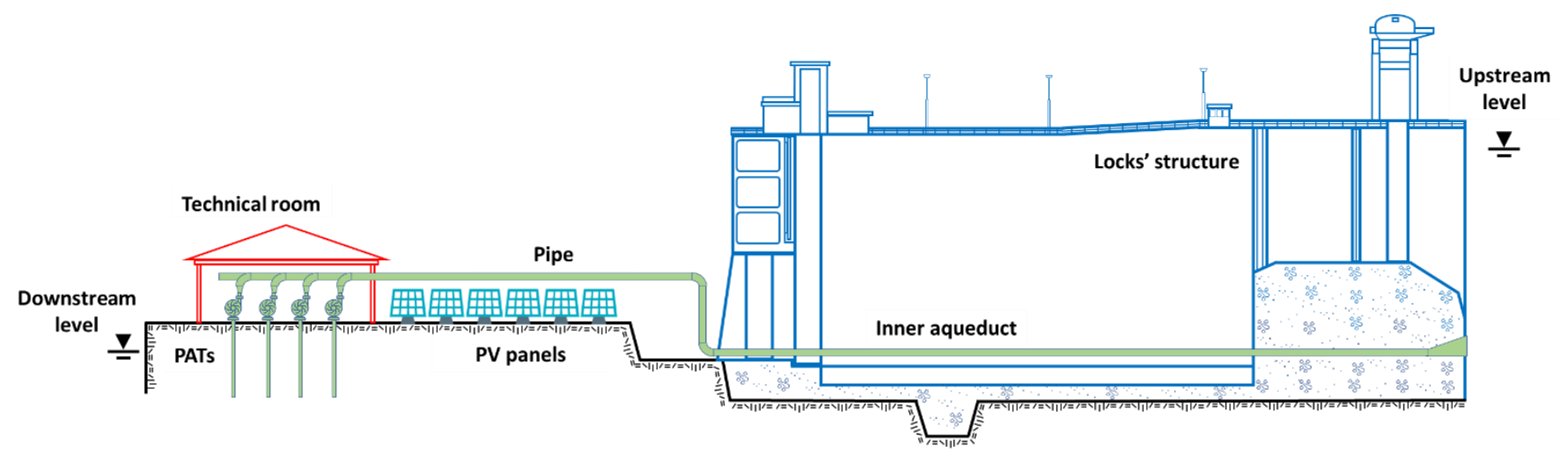

Figure 7. Schematic representation of the installation.

The system curves were calculated from Bernoulli, Equation (16), applied between the upstream and downstream levels for loss determination and between the downstream and suction pump levels for calculating the net positive suction head for cavitation checking, both considering the dimensions and characteristics of the hydraulic system such as piping, fittings, head etc., according to Figure 8, where all points and lines refer to the pipe and pipe fitting.

$$
\frac{p_{4}}{\rho g}+\alpha_{4} \frac{U_{4}^{2}}{2 g}+z_{4}=\frac{p_{1}}{\rho g}+\alpha_{1} \frac{U_{1}^{2}}{2 g}+z_{1}+\frac{h_{l T}}{g}
$$

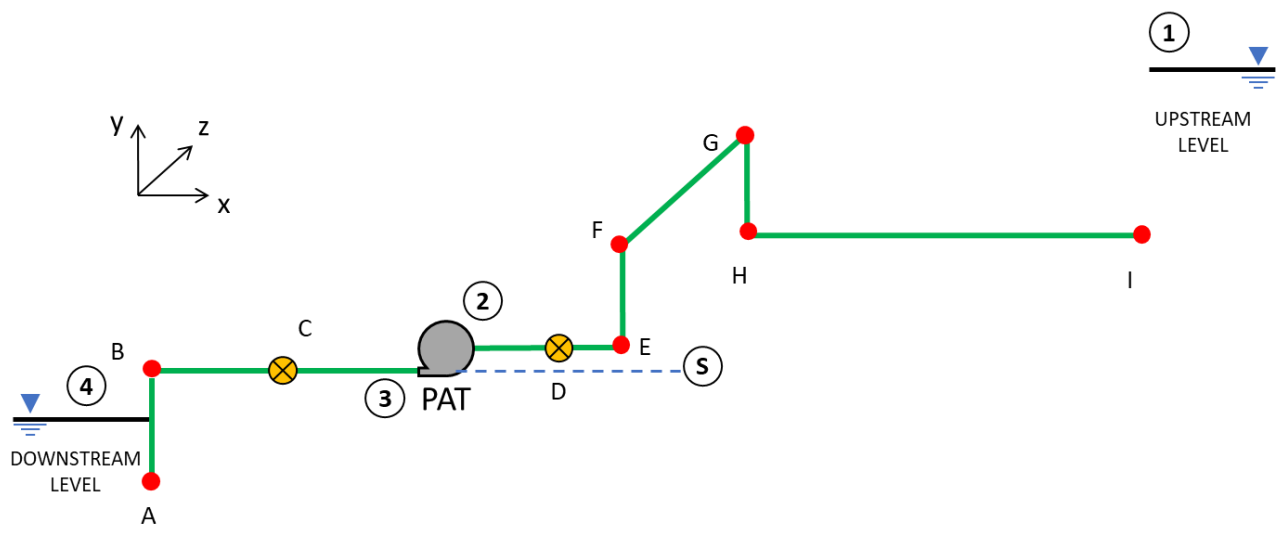

Figure 8. Hydraulic system diagram for the pipeline.

\subsection{Variable rotational speed}

From the selected pump, the following procedure was performed to calculate the machine operating in variable rotational speed, guaranteed by a dedicated control system. Equations (17) shows the generic form of the pump and system equations, respectively.

$$
H_{b}=a+b Q+c Q^{2} \quad \text { and } \quad H_{s}=d_{s}+e_{s} Q^{2}
$$


By the similarity law for pump, the quantities rotation $N$, flow rate $Q$, head $H$ and power $P$ are related to the form of Equations (18), in their initial and final conditions. To change the operating point in this pumping system was chosen by shifting the pump curve, to ensure greater efficiency, compared to changing the system curve by inserting pressure losses.

$$
\frac{Q_{1}}{Q_{2}}=\frac{N_{1}}{N_{2}} \quad ; \quad \frac{H_{1}}{H_{2}}=\left(\frac{N_{1}}{N_{2}}\right)^{2} \quad ; \quad \frac{P_{1}}{P_{2}}=\left(\frac{N_{1}}{N_{2}}\right)^{3}
$$

By combining Equations (17) and (18) and the operating point, the following relationship in $N_{2}$ can be found as an equation of the second degree as a function of known pump and installation characteristics.

$$
\begin{aligned}
& \quad\left[\frac{a}{N_{1}^{2}}\right] N_{2}^{2}+\left[b \frac{Q_{r e q}}{N_{1}}\right] N_{2}+\left[Q_{r e q}^{2}\left(c-\frac{H_{a t}-H_{0}}{Q_{a t}^{2}}\right)-H_{0}\right]=0 \\
& A=\frac{a}{N_{1}^{2}} \\
& B=b \frac{Q_{r e q}}{N_{1}} \\
& C=Q_{r e q}^{2}\left(c-\frac{H_{a t}-H_{0}}{Q_{a t}^{2}}\right)-H_{0}
\end{aligned}
$$

Therefore, having the new required flow rate $Q_{r e q}$, the new speed rotation can be determined by the solution of Equation (19). A new pump curve at the new rotation $N_{2}$ can also be calculated from Equations (18). Thus, from the curves of losses, selected pump, similarity law and parallel pump theory, Figure 9 represents the operational field of the system in pump mode.

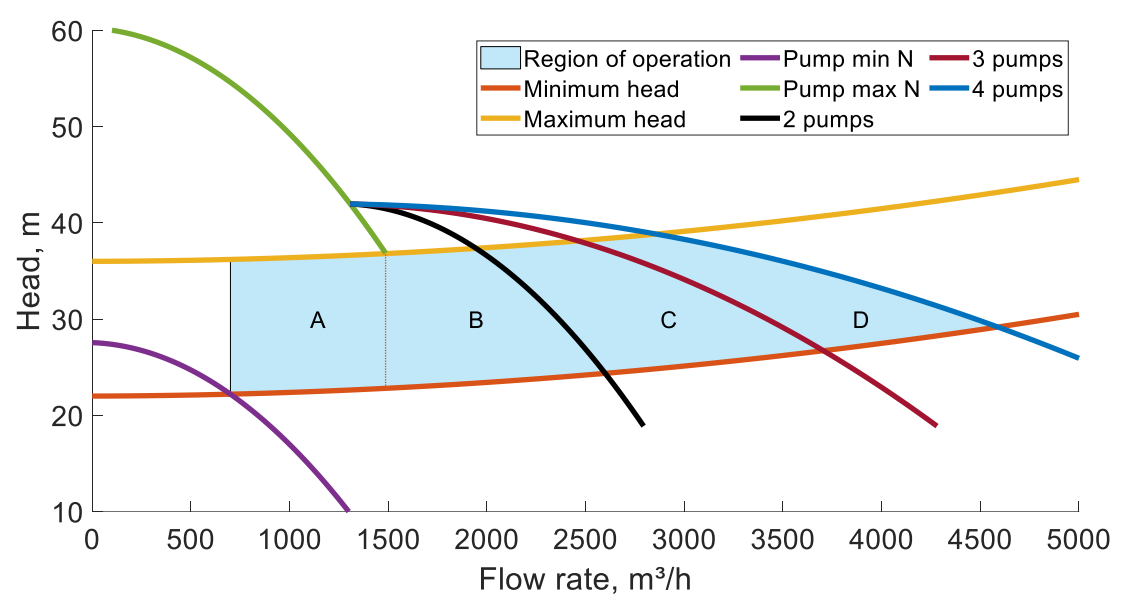

Figure 9. Pump mode system operation prediction.

In the configuration shown in Figure 9 it is possible to note that only one machine operating at variable speed associated with the others three operating at fixed rotation guarantees the pumping in the whole flow rate and head range of the installation. This chart highlights four distinct regions that represent the possible operating areas for each set of machines. In region A pumping requirements are met by a single pump operating at variable speed. In the event of increased pumping energy, the facility operates in region $B$ with the start of one more machine at a fixed speed. As the demanded flow 
increases other fixed speed units come into operation in regions $C$ and $D$ respectively. All cases respect the limits set by the pump manufacturers.

The forecast for operating the system in reverse mode is shown in Figure 10. Two methodologies were associated to establish the speed limits for PAT and, consequently, the region of operation. Morabito and Hendrick [18] use a statistical/empirical formulation based on subgroups defined by the diameter of the impeller that lead to better match with the experimental values of $h$ and $q[34,37]$. For the project's impeller diameter of $0.282 \mathrm{~m}$, Equations (23) and (24) are valid, which depend on the specific speed of the pump $N_{S p}$, in Equation (25), and provide the best efficiency point in turbine mode.

$$
\begin{aligned}
& h=5.196 N_{S p}^{-0.323} \\
& q=3.127 N_{S p}^{-0.219} \\
& N_{S p}=N_{P} \sqrt{Q_{P}} /\left(H_{P}\right)^{0.75}
\end{aligned}
$$

Rossi et al. [38] present an interesting approach to predict the behavior of a pump operating as a turbine, based on the turbine's BEP. The authors establish a normalized mathematical relationship between the non-dimensional coefficients for pressure, flow rate and efficiency to plot the characteristic curves of PAT. The curves shown in Figure 10 were calculated by Equations (26) to (30). Formulation in which the characteristics of flow rate, head, speed rotation, diameter of impeller, specific speed and efficiency of the selected machine are compatible.

$$
\begin{aligned}
& \psi / \psi_{B E P_{t}}=0.2394 R^{2}+0.769 R \\
& \eta / \eta_{B E P_{t}}=-1.9788 R^{6}+9.0636 R^{5}-13.148 R^{4}+3.8527 R^{3}+4.5614 R^{2}-1.3769 R \\
& R=\phi / \phi_{B E P_{t}} \\
& \phi=Q /\left(N D^{3}\right) \\
& \psi=g H /(N D)^{2}
\end{aligned}
$$

The behavior described is a prediction for the variable speed PAT under three different conditions: the nominal curve and two others that represent the maximum and minimum speeds necessary to guarantee the operation within region $A$. Although the general theoretical prediction of the operation is shown, detailing the behavior of the machine in turbine mode including its operation in parallel and the influence of efficiency in generation will be topics addressed in a future paper. 


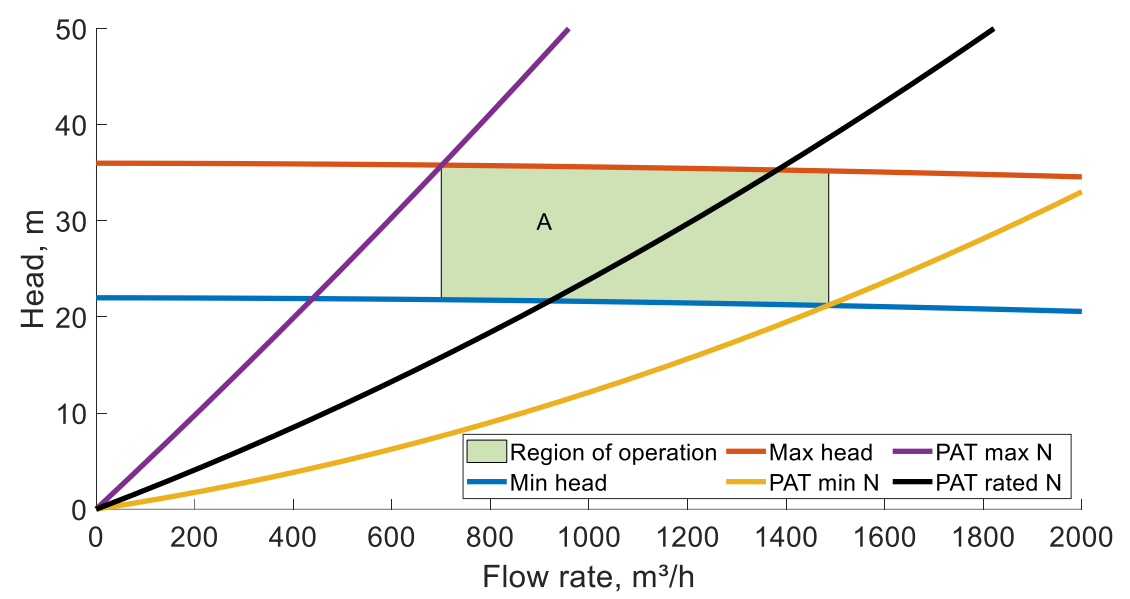

Figure 10. Turbine mode system operation prediction.

\subsection{Cost of energy}

The energy tariffs in Brazil vary according to Table 2. The calculated costs for the payback evaluation for the studied alternatives, took into account the hourly cost for each solution. These results were projected annually, considering the variations of the tariff for working days and weekends. The tariffs shown in Table 2 represent the values applicable by the local power distribution company and, therefore, differ from other states in the country.

Table 2. Energy tariff in the region (US\$/kWh).

\begin{tabular}{l|c|c|c|c}
\hline \multicolumn{1}{c|}{ Tariff station } & Pick time & \multicolumn{2}{|c|}{ Intermediary } & Off pick time \\
\hline Hour (h) & $18: 30$ to $21: 29$ & $17: 30$ to $18: 29$ & $21: 30$ to $22: 29$ & $22: 30$ to $17: 29$ \\
\hline Tariff (working days) & 0.34936 & \multicolumn{2}{|c|}{0.22415} & 0.13773 \\
\hline Tariff (weekend) & \multicolumn{3}{|c|}{0.13773} \\
\hline
\end{tabular}

Exchange ref. 09/29/2019.

The costs of energy supplied by the grid for one day were calculated from the hourly basis for working days and weekend separately based on Equations (31) and (32). TOE represents the tariff of energy according to the data in Table 2, which follows the rule of the Brazilian National Electric Energy Agency [39, 40]. The cost of energy over time has been calculated by Equations (33) and (34), where $t$ is the year.

$$
\begin{gathered}
C O E_{w d}=\sum d_{e} T O E_{w d} \\
C O E_{w k}=\sum d_{e} T O E_{w k} \\
C O E_{c_{y e a r}}=365 / 7\left(5 C O E_{w d}+2 C O E_{w k}\right) \\
C O E_{c}=t \cdot C O E_{c_{y e a r}}
\end{gathered}
$$

Energy costs for photovoltaic and hybrid alternatives were calculated according to Equations (35) and (36), considering capital costs plus operation and maintenance costs. It was adopted the suggestion of Jannuzzi and Melo [28] which considers the $O \& M$ costs of these installations to be $1 \%$ of the capital cost for photovoltaic systems. For the hybrid case the estimate used was $2 \%$. 


$$
\begin{gathered}
C O E_{P V}=C_{c a p_{P V}}+t \cdot C_{O \& M_{P V}} \\
C O E_{H y b}=C_{c a p_{H y b}}+t \cdot C_{O \& M_{H y b}}
\end{gathered}
$$

In turn, the capital costs for solar and hybrid alternatives was determined based on Equations (37) and (38), which consider the cost of availability $C_{A v}$, under the rules of the Brazilian energy regulator, regarding the use of transmission system and the financial estimate for implementation of photovoltaic systems in Brazil $C_{P V}$ of $1.8 U S \$ / W_{p}$. For the hybrid case, the cost of acquiring the equipment $C_{A q}$ was added to these.

$$
\begin{gathered}
C_{c a p_{P V}}=C_{A v}+C_{P V} P_{m 1} \\
C_{c a p_{H y b}}=C_{A q}+C_{A v}+C_{P V} P_{m 2}
\end{gathered}
$$

In comparison to the purely photovoltaic system, the hybrid system design incorporates hydraulic components such as the centrifugal pump, piping and accessories in the cost composition, in addition to the driver and supervision equipment. Research in the Brazilian market to prepare the project budget showed that the rate between the cost of purchasing hydraulic equipment and the total cost of the hybrid system $C_{A q} / C_{c a p_{H y b}}$ is in the order of about $26 \%$, although it may vary by be based on commercial estimates.

\subsection{Payback time}

To determine the payback time for each alternative, Equations (34) and (37) were combined for the photovoltaic-only case and Equations (34) and (38) for the hybrid case, as follows.

$$
\begin{gathered}
t_{P V}=C_{\text {cap }_{P V}} /\left(C O E_{c_{\text {year }}}-C_{O \& M_{P V}}\right) \\
t_{H y b}=C_{c a p_{H y b}} /\left(C O E_{c_{\text {year }}}-C_{O \& M_{H y b}}\right)
\end{gathered}
$$

\section{RESULTS AND DISCUSSION}

\subsection{Photovoltaic-only alternative}

For the purely photovoltaic system, the power of $1569 \mathrm{~kW}$ is obtained by the 4757 photovoltaic modules, occupying an area of $9249 \mathrm{~m}^{2}$. Figure 11 shows the comparison between hourly demand and photovoltaic production. The solar energy shown was calculated according to equation (5). The graph, with sunshine data for the critical month (December), shows that solar production meets the demand for operation, guaranteeing in the daily balance a surplus stored in the grid of about $1500 \mathrm{kWh}$. 


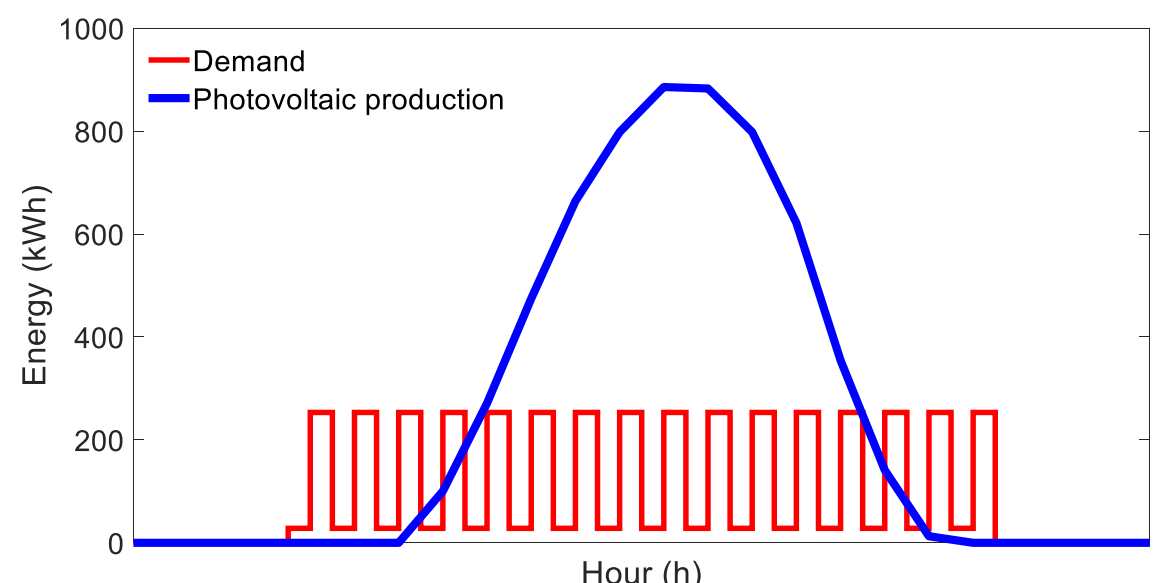

Figure 11 . Hourly demand and photovoltaic production $\left(N_{P V 1}=4657\right)$.

\subsection{Hybrid system alternative}

Figure 12 presents the energy production by the installed photovoltaic arrays and by the PAT. In this system, the use of factor $\alpha$ causes a reduction in the same proportion of occupied area, installed power and number of panels, in relation to the purely photovoltaic alternative. In this arrangement, the PAT guarantees the necessary complement for supplying the energy for operation, taking into account the balance at each moment, according to Equation (9). It is observed that the negative energy values represent energy consumed by the pump for storing the energy. This chart represents a case among the possible combinations of solar irradiation and demand. Therefore, in this hybrid system, the variation of the operating point in the pump to ensure energy supply is ensured by a dedicated speed control system, the object of research and detail in future articles.

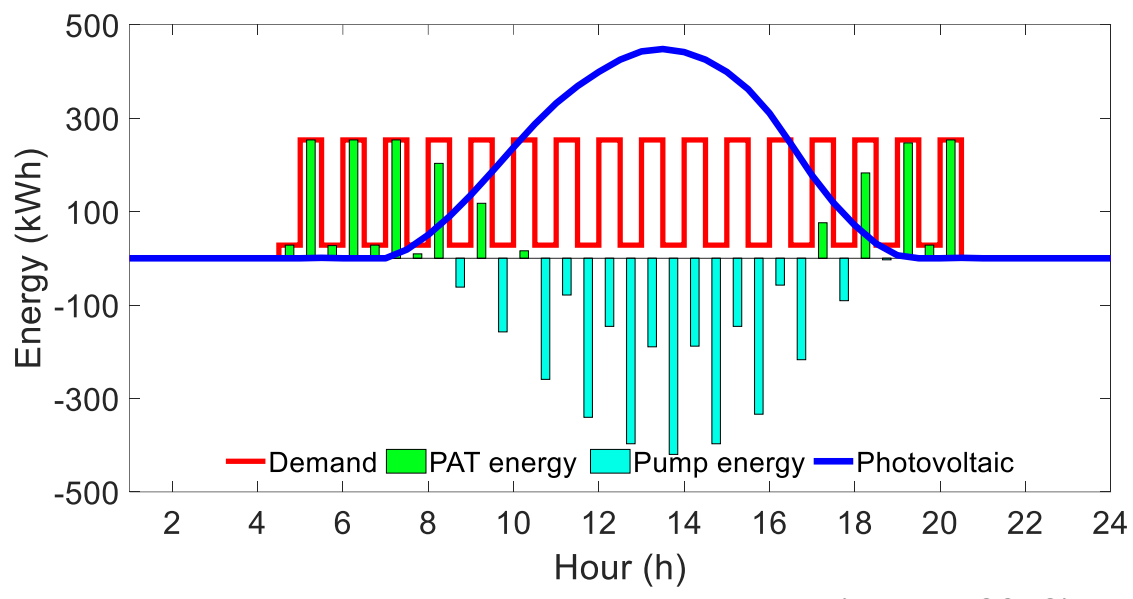

Figure 12. Power production in the hybrid system $\left(N_{P V 2}=2378\right)$.

\subsection{Operation scheme}

From the analysis of Figure 12 it can be observed that the mode of operation of the PAT depends on the balance between demand and photovoltaic production at each moment. Thus, due to the intermittent variation of the demand, it would be necessary to have a high number of conversions in the machines, besides operation in different conditions of power, rotation etc. To prevent the problems arising from this type of operation in mechanical and electrical equipment, the use of the grid as an intermediate means of energy storage is proposed, taking into account the energy tariffs presented in Table 2. Thus, it is possible to establish a new continuous and economical scheme for pump mode operation and only one conversion to turbine mode, as shown in Figure 13. In this case, while the intermittent consumption of the plant is supplied by the grid, the charge controller manages consumption and production at PAT to ensure at the end of the day the balance in demand, generation and consumption. 


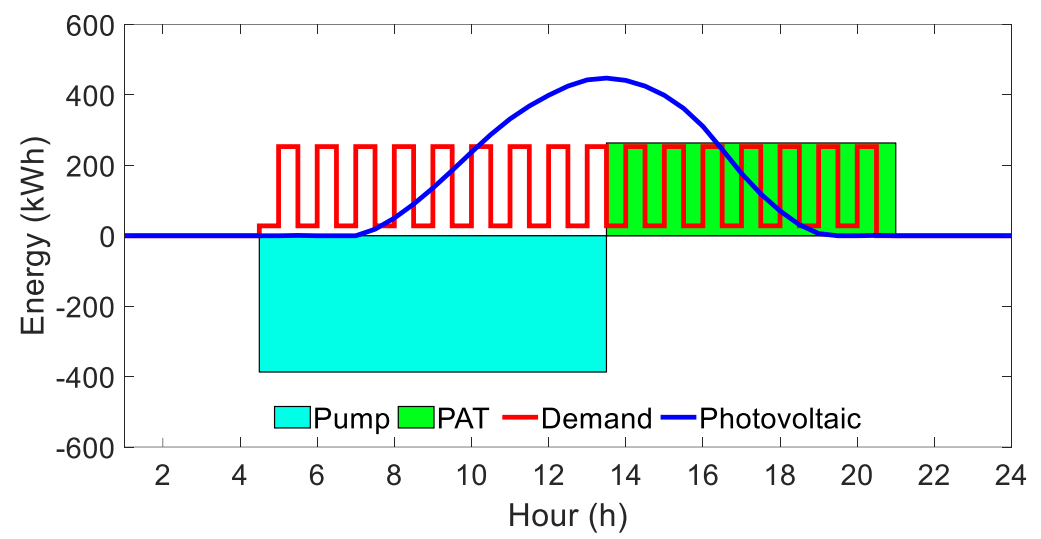

Figure 13. Hybrid system operation scheme.

\subsection{Use of water resource}

The hybrid system, proposed for installation in the Tucuruí Locks, is designed to take advantage of renewable energy, without interfering with the local hydrological dynamics, in order to maintain constant amounts of turbine and pumped water. In this sense, Figure 14 shows the use of water in each mode of operation. It is possible to note that the cumulative volume of pumped water is turbined in the sequence, after conversion to the reverse mode. The different slopes in the volume curves reflect the operation at different flow rates, so as to ensure the equality established by Equation (13). Based on the operation scheme shown in Figure 13, volumes were calculated as a linear function of PAT operating time.

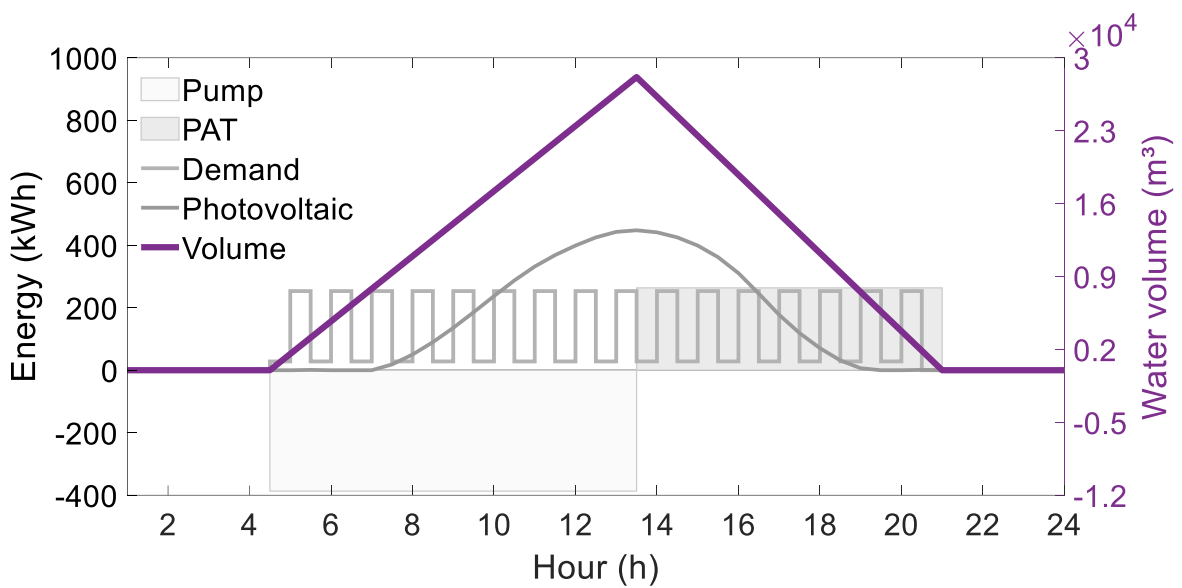

Figure 14. Use of water in hybrid generation process.

\subsection{Energy Payback time}

Figure 15 shows the comparison between the proposed solutions and the conventional case, without own generation. The curves were calculated according to Equations (35) and (36). It should be noted that among the alternatives the hybrid system presents better payback (6.8 years) compared to the pure photovoltaic system (11.2 years). 


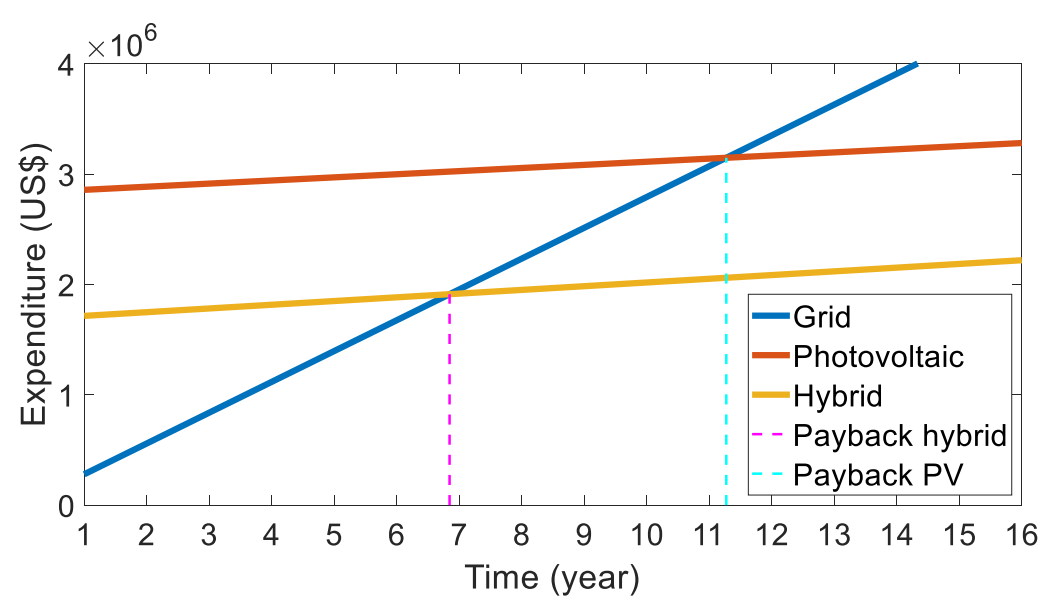

Figure 15. Comparison of energy alternatives payback.

Photovoltaic energy solutions are widely explored in the literature, applied in several cases aiming at autonomy, respect for the environment, laws and economic viability. The payback time is one of the aspects addressed to assess the viability of a project. These values vary with the specifics of each project. In systems where photovoltaic technology is present, paybacks of 2.3 [41], 4.1 [42], 4.9 [43], 6 [44], 7.4 [45] and 9.6 years [46] are reported, noting that among several photovoltaic technologies the expected payback values are less than 10 years [46].

An additional consideration about the time to return on investment refers to the influence of the powerplant adjacent to the facility. During humid period, typically from February to May the dam spillway operates continuously.

Considering that during this season there is no need for pumping, the amount of energy consumed in the pump mode (Figure 13) is discounted from the demand for calculation of the hybrid system, Equation (6), resulting in a reduction in the quantities $P_{m 2}, N_{P V 2}$ and $E_{s 2}$, consequently decreasing the return on investment time shown in Equation (40). In this way, the humid period allows the hybrid installation a constant operation in turbine mode without the need for storage. This feature causes an important reduction in payback to 5.2 years, as can be seen in Figure 16.

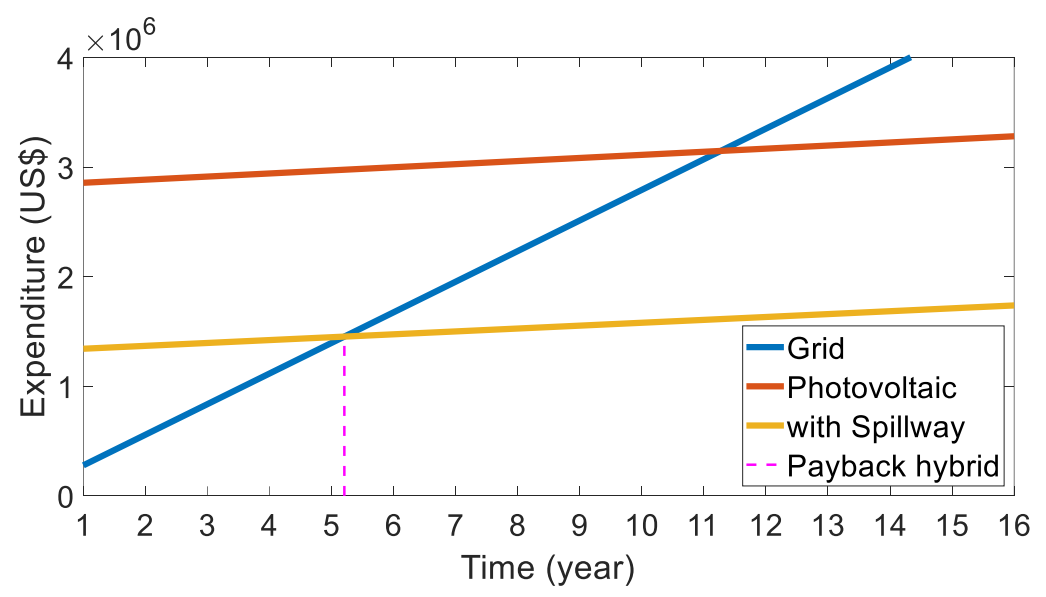

Figure 16. Payback time considering humid period.

\subsection{Scenarios Analysis}

By way of example, Figure 17 shows a history of spillway operation over 5 years to show the variability of the operation. Its operation depends on hydrological factors subject to natural variations. In this way, in different years, the equipment can operate for up to four consecutive months or until it does not go into operation, as in 2016. Considering this aspect, Figure 18 shows the influence of this spillway, installed in the dam adjacent to the project, with which the upper reservoir is divided, in the payback time of the proposed project. This figure describes the return on investment according to the behavior of the equipment under the following conditions: without going into operation, operating for only one month and 2 to 4 months of opening over a year. It is noted, therefore, that in the absence of storage, the proposed system presents a faster return to the investor. 


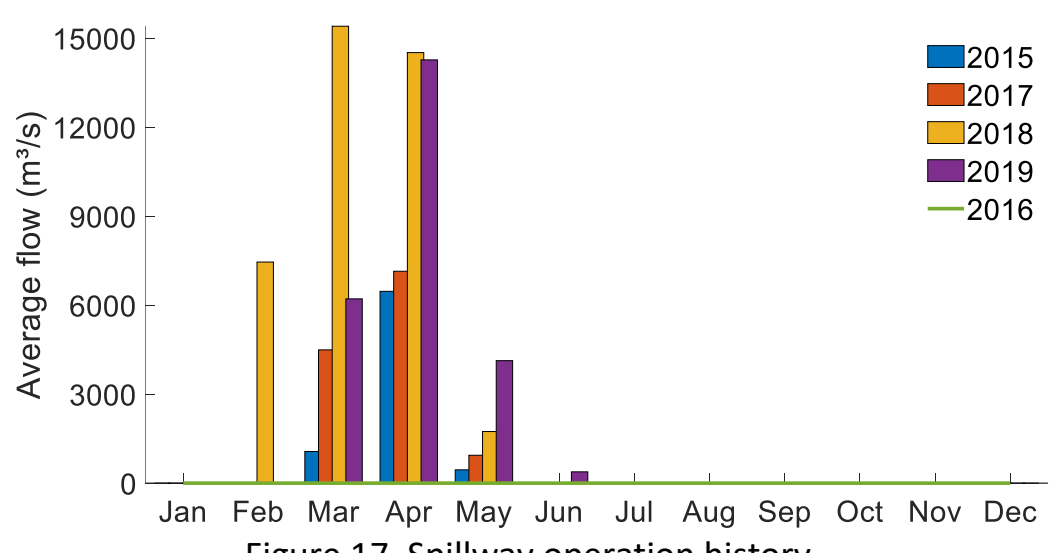

Figure 17. Spillway operation history.

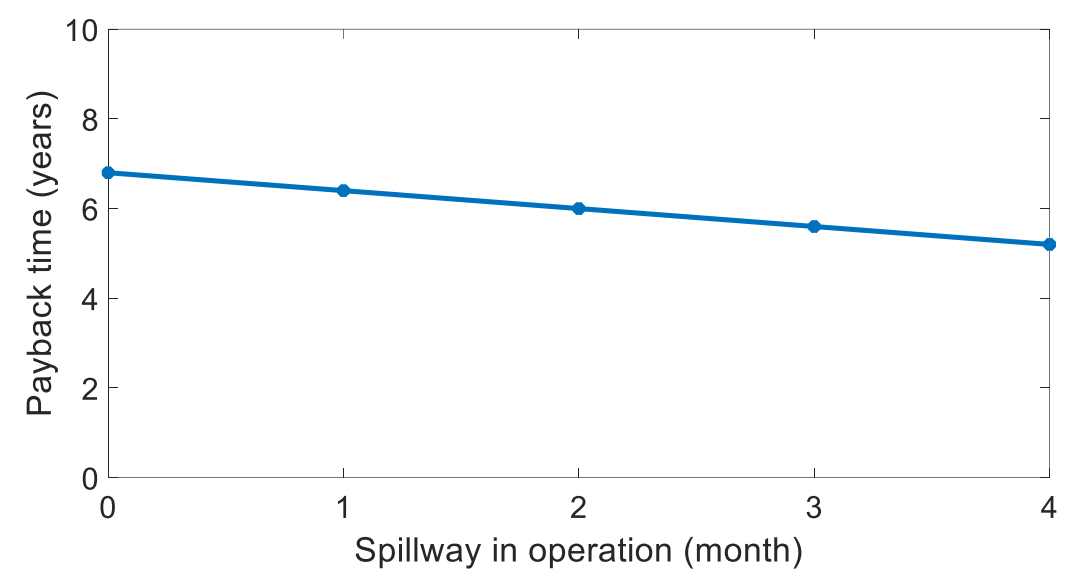

Figure 18. Influence of adjacent spillway operation on project's payback.

The use of renewable sources in energy generation systems has the characteristic of variability that needs to be considered in different scenarios in order to make better use of the resource. Wang and Huang [35] demonstrate the importance of cooperative energy planning between different sources and their impact on total generation costs, in addition to an optimization proposal to minimize investment costs [36]. In this sense, Figure 19 exemplifies the average daily variation in different months of irradiation at the project's site and the head profile, configuring different availability conditions.
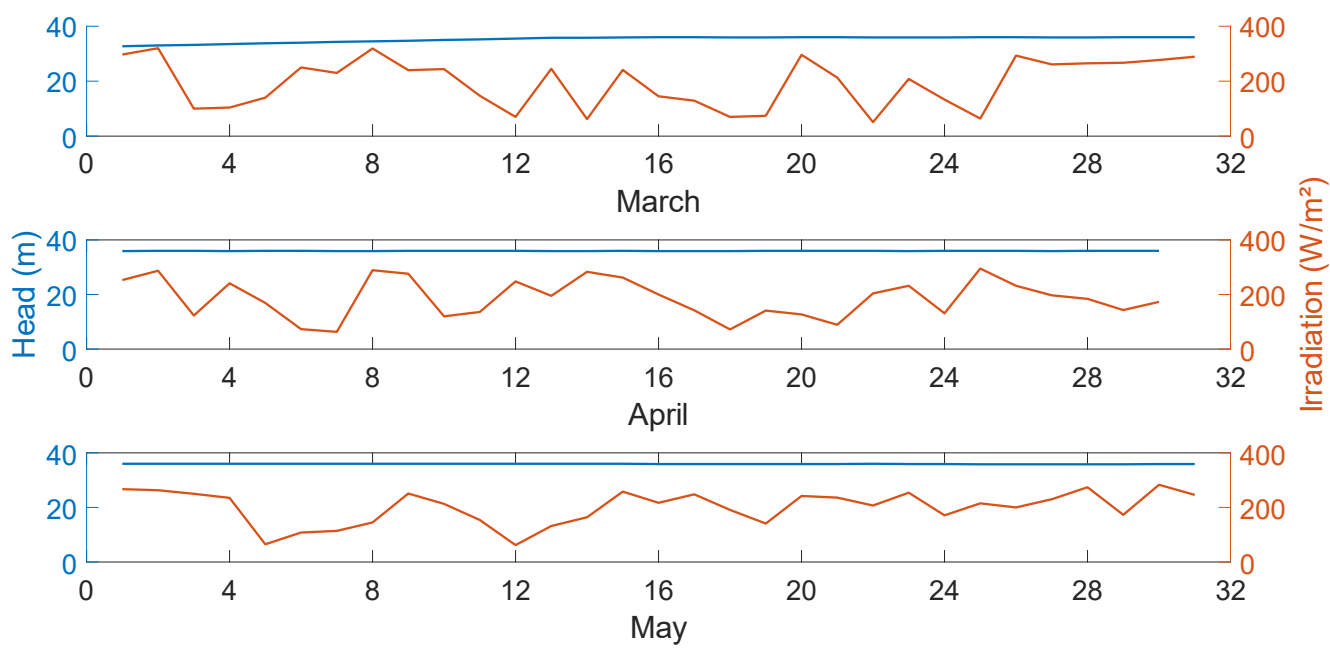

Figure 19. Scenarios of solar availability and head for different months of the year. 
A general overview of the system's expected production is described in Figure 20. The graph shows the capabilities of the hybrid system in the design condition. Being sizing based on the month with the lowest irradiation and head (December), it presents additional storage capacity for the months with greater solar availability.

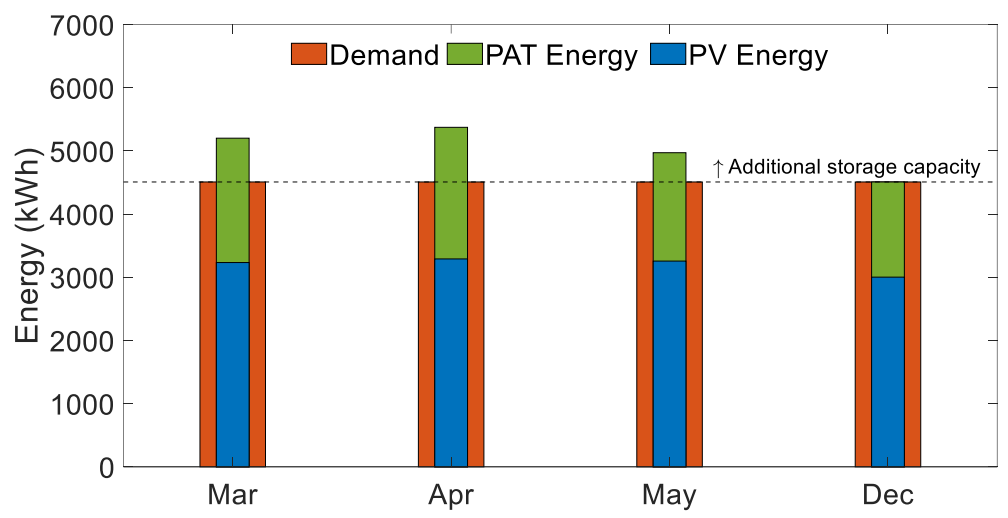

Figure 20. Energy capacity of the hybrid system in different months.

\section{CONCLUSIONS}

The installed global capacity of renewable energy grows steadily every year, and more environmentally friendly and costeffective facilities are designed according to the specificity of the site $[17,18,20]$.

The project for energy solution of the Lock operations studied by Zhang et al. [22] proposes the use of a hydraulic turbine with variable rotational speed for the exploitation of the fluctuating flow rate and available head. This work, in turn, explores other designing key-factors crucial for analyzing the energy options offered by solar and hydraulic sources. This paper provides the much-sought information regarding a hybrid energy source system to be implemented to waterways locks and dams, promoting the growing debate in energy sustainability.

The alternatives studied in this paper are presented as viable solutions at the installation at Tucuruí Locks. This work, with the objective of comparing different renewable energy sources, showed that the hybrid solar-hydraulic system with pumped storage is more economically and technically feasible for this case study.

In the specificity of this project, the grid is used as an intermediate storage and it allows the system to operate with a single pump/pump as turbine conversion, preventing excessive number of starts and stops, faults, defects and, consequently, maintenance. In this way, the balance is passed at the end of the day of operation.

The presence of the existing structures for hydrological exploitation and the high costs for a stand-alone photovoltaic installation provide the opportunity of a pumped storage application for a more efficient and cheaper energy source installation. In addition to the lower initial investment for this scenario, the energy expenditure for the hybrid system proposed compared to the utility's supply costs leads to a shorter payback time (around $-40 \%$ ) because of the available head and the high costs of a pure photovoltaic plant.

Another advantage also depicted by Xu et al. [17] is that the pumped storage integrated with solar source allows to a better absorption of fluctuations due to photovoltaic variability, favoring the optimal use of the sources.

Regarding a conscientious use of the water resource, the option of a hybrid system guarantees a responsible use of the installation in respect of the environment by manipulating the water for energy use without additional impact on the existing hydrological dynamics.

As shown, the operation of the spillway causes an important influence on the facility outcomes, within regards to economic and operational aspects. In the future work, this approach will be carried out based on a statistical analysis of the historical series of the spillway's opening for further investigation in the energy solution of waterways locks.

Finally, the potential of using Locks for energy generation and storage was demonstrated, when associated with the use of renewable solar and hydraulic sources, as an innovative opportunity taking advantage of the head and the solar availability, improving the financial return on meeting the energy demand for operation through an economically advantageous and environmentally responsible system. 


\section{ACKNOWLEDGEMENT}

Authors wish to acknowledge the assistance from National Department of Transport Infrastructure (DNIT), Carlos Gil of Eletrobras Eletronorte for data and site visits, CNPq (Proc. n. 307241/2018-1) and PROPESP/UFPA for all support in this project. Authors also wish to thank the WBI in the frame of CAPES program and EPOC project, funded by Federal Public Service of Economy of Belgium.

\section{REFERENCE}

[1] Brebbia CA. Urban Transport XX. Volume 138 of WIT Transactions on The Built Environment. WITPress; 2014.

[2] Curtarelli MP, Ogashawara I, de Araújo CAS, Lorenzzetti JA, Leão JAD, Alcântara E, et al. Carbon dioxide emissions from Tucuruí reservoir (Amazon biome): New findings based on three-dimensional ecological model simulations. Sci Total Environ 2016;551-552:676-94. https://doi.org/10.1016/j.scitotenv.2016.02.001.

[3] Chen G, Powers RP, de Carvalho LMT, Mora B. Spatiotemporal patterns of tropical deforestation and forest degradation in response to the operation of the Tucuruí hydroelectricdam in the Amazon basin. Appl Geogr 2015;63:1-8. https://doi.org/10.1016/j.apgeog.2015.06.001.

[4] Bhattacharjee S, Nayak PK. PV-pumped energy storage option for convalescing performance of hydroelectric station under declining precipitation trend. Renew Energy 2019;135:288-302. https://doi.org/10.1016/j.renene.2018.12.021.

[5] Sun K, Li KJ, Pan J, Liu Y, Liu Y. An optimal combined operation scheme for pumped storage and hybrid windphotovoltaic complementary power generation system. Appl Energy 2019;242:1155-63. https://doi.org/10.1016/j.apenergy.2019.03.171.

[6] Javed MS, Ma T, Jurasz J, Amin MY. Solar and wind power generation systems with pumped hydro storage: Review and future perspectives. Renew Energy 2020;148:176-92. https://doi.org/10.1016/j.renene.2019.11.157.

[7] Rehman S, Al-Hadhrami LM, Alam MM. Pumped hydro energy storage system: A technological review. Renew Sustain Energy Rev 2015;44:586-98. https://doi.org/10.1016/j.rser.2014.12.040.

[8] Kumar A, Biswas A. Techno-economic optimization of a stand-alone PV/PHS/battery systems for very low load Situation. Int J Renew Energy Res 2017;7:844-56.

[9] Lian J, Zhang Y, Ma C, Yang Y, Chaima E. A review on recent sizing methodologies of hybrid renewable energy systems. Energy Convers Manag 2019;199:112027. https://doi.org/10.1016/j.enconman.2019.112027.

[10] Ma T, Yang H, Lu L, Peng J. Pumped storage-based standalone photovoltaic power generation system: Modeling and techno-economic optimization. Appl 2015;137:649-59. https://doi.org/10.1016/j.apenergy.2014.06.005.

[11] Malheiro A, Castro PM, Lima RM, Estanqueiro A. Integrated sizing and scheduling of wind/PV/diesel/battery isolated systems. Renew Energy 2015;83:646-57. https://doi.org/10.1016/j.renene.2015.04.066.

[12] Aziz AS, Tajuddin MFN, Adzman MR, Ramli MAM, Mekhilef S. Energy management and optimization of a PV/diesel/battery hybrid energy system using a combined dispatch strategy. Sustain 2019;11. https://doi.org/10.3390/su11030683.

[13] Ma T, Yang H, Lu L, Peng J. Optimal design of an autonomous solar-wind-pumped storage power supply system. Appl Energy 2015;160:728-36. https://doi.org/10.1016/j.apenergy.2014.11.026.

[14] Pali BS, Vadhera S. A novel pumped hydro-energy storage scheme with wind energy for power generation at constant voltage in rural areas. Renew Energy 2018;127:802-10. https://doi.org/10.1016/j.renene.2018.05.028.

[15] Kusakana K. Optimal scheduling for distributed hybrid system with pumped hydro storage. Energy Convers Manag 2016;111:253-60. https://doi.org/10.1016/j.enconman.2015.12.081.

[16] Chaudhary P, Rizwan M. Energy management supporting high penetration of solar photovoltaic generation for smart grid using solar forecasts and pumped hydro storage system. Renew Energy 2018;118:928-46. https://doi.org/10.1016/j.renene.2017.10.113.

[17] Xu B, Chen D, Venkateshkumar M, Xiao Y, Yue Y, Xing Y, et al. Modeling a pumped storage hydropower integrated to a hybrid power system with solar-wind power and its stability analysis. Appl Energy 2019;248:446-62. https://doi.org/10.1016/j.apenergy.2019.04.125.

[18] Morabito A, Hendrick P. Pump as turbine applied to micro energy storage and smart water grids: A case study. Appl Energy 2019;241:567-79. https://doi.org/10.1016/j.apenergy.2019.03.018. 
[19] Ma T, Javed MS. Integrated sizing of hybrid PV-wind-battery system for remote island considering the saturation of each renewable energy resource. Energy Convers Manag 2019;182:178-90. https://doi.org/10.1016/j.enconman.2018.12.059.

[20] Javed MS, Zhong D, Ma T, Song A, Ahmed S. Hybrid pumped hydro and battery storage for renewable energy based power supply system. Appl Energy 2020;257:114026. https://doi.org/10.1016/j.apenergy.2019.114026.

[21] Stenzel P, Linssen J. Concept and potential of pumped hydro storage in federal waterways. Appl Energy 2016;162:486-93. https://doi.org/10.1016/j.apenergy.2015.10.033.

[22] Zhang J, Leontidis V, Dazin A, Tounzi A, Delarue P, Caignaert G, et al. Canal lock variable speed hydropower turbine design and control. IET Renew Power Gener 2018;12:1698-707. https://doi.org/10.1049/iet-rpg.2018.5312.

[23] Esen H, Inalli M, Esen M. Technoeconomic appraisal of a ground source heat pump system for a heating season in eastern Turkey. Energy Convers Manag 2006;47:1281-97. https://doi.org/10.1016/j.enconman.2005.06.024.

[24] Esen H, Inalli M, Esen M. A techno-economic comparison of ground-coupled and air-coupled heat pump system for space cooling. Build Environ 2007;42:1955-65. https://doi.org/10.1016/j.buildenv.2006.04.007.

[25] Esen M, Yuksel T. Experimental evaluation of using various renewable energy sources for heating a greenhouse. Energy Build 2013;65:340-51. https://doi.org/10.1016/j.enbuild.2013.06.018.

[26] Ministry of Transport. Map of the main Dams and Locks in Brazil 2012:7233.

[27] DNIT - National Department of Transport Infrastructure. Tucuruí Locks-PA 2020:1. http://www.dnit.gov.br/hidrovias/obras-da-diretoria-aquaviaria/eclusas/eclusa-de-tucurui-pa.

[28] Jannuzzi G de M, de Melo CA. Grid-connected photovoltaic in Brazil: Policies and potential impacts for 2030. Energy Sustain Dev 2013;17:40-6. https://doi.org/10.1016/j.esd.2012.10.010.

[29] Rüther R, Zilles R. Making the case for grid-connected photovoltaics in Brazil. Energy Policy 2011;39:1027-30. https://doi.org/10.1016/j.enpol.2010.12.021.

[30] Martins FR, Pereira EB, Silva SAB, Abreu SL, Colle S. Solar energy scenarios in Brazil, Part one: Resource assessment. Energy Policy 2008;36:2853-64. https://doi.org/10.1016/j.enpol.2008.02.014.

[31] Martins FR, Rüther R, Pereira EB, Abreu SL. Solar energy scenarios in Brazil. Part two: Photovoltaics applications. Energy Policy 2008;36:2865-77. https://doi.org/10.1016/j.enpol.2008.04.001.

[32] Pinho JT, Galdino MA. Engineering Manual for Photovoltaic Systems. Rio de Janeiro: CEPEL-CRECESB; 2014.

[33] CRESESB RC for wind and solar energies S de SB. Irradiação Solar no Plano Horizontal para Tucurui , PA - BRASIL. CEPEL - Electr Energy Res Cent 2020:4-6. http://www.cresesb.cepel.br/index.php\#data.

[34] Derakhshan S, Nourbakhsh A. Experimental study of characteristic curves of centrifugal pumps working as turbines in different specific speeds. Exp Therm Fluid Sci 2008;32:800-7. https://doi.org/10.1016/j.expthermflusci.2007.10.004.

[35] Wang H, Huang J. Cooperative Planning of Renewable Generations for Interconnected Microgrids. IEEE Trans Smart Grid 2016;7:2486-96. https://doi.org/10.1109/TSG.2016.2552642.

[36] Wang H, Huang J. Joint Investment and Operation of Microgrid. IEEE Trans Smart Grid 2017;8:833-45. https://doi.org/10.1109/TSG.2015.2501818.

[37] Singh P, Nestmann F. A consolidated model for the turbine operation of centrifugal pumps. J Eng Gas Turbines Power 2011;133:1-9. https://doi.org/10.1115/1.4002270.

[38] Rossi M, Nigro A, Renzi M. Experimental and numerical assessment of a methodology for performance prediction of Pumps-as-Turbines (PaTs) operating in off-design conditions. Appl Energy 2019;248:555-66. https://doi.org/10.1016/j.apenergy.2019.04.123.

[39] National Electric Energy Agency. Normative Resolution 414/2010. 2010.

[40] National Electric Energy Agency. Normative Resolution 2.433/2018. 2018.

[41] Wu P, Ma X, Ji J, Ma Y. Review on life cycle assessment of energy payback of solar photovoltaic systems and a case study. Energy Procedia 2017;105:68-74. https://doi.org/10.1016/j.egypro.2017.03.281.

[42] Bhandari KP, Collier JM, Ellingson RJ, Apul DS. Energy payback time (EPBT) and energy return on energy invested (EROI) of solar photovoltaic systems: A systematic review and meta-analysis. Renew Sustain Energy Rev 2015;47:133-41. https://doi.org/10.1016/j.rser.2015.02.057.

[43] Asdrubali F, Ballarini I, Corrado V, Evangelisti L, Grazieschi G, Guattari C. Energy and environmental payback times for an NZEB retrofit. Build Environ 2019;147:461-72. https://doi.org/10.1016/j.buildenv.2018.10.047. 
[44] Kaldellis JK, Zafirakis D, Kondili E. Energy pay-back period analysis of stand-alone photovoltaic systems 2010;35:1444-54. https://doi.org/10.1016/j.renene.2009.12.016.

[45] Huang D, Yu T. Study on Energy Payback Time of Building Integrated Photovoltaic System. Procedia Eng 2017;205:1087-92. https://doi.org/10.1016/j.proeng.2017.10.174.

[46] Armendariz-lopez JF, Arena-granados AP, Gonzalez-trevizo ME, Luna-Leon A, Bojorquez-Morales G. Energy payback time and Greenhouse Gas emissions: Studying the international energy agency guidelines architecture. J Clean Prod 2018;196:1566-75. https://doi.org/10.1016/j.jclepro.2018.06.134. 